\title{
EML4-ALK translocation is associated with early onset of disease and other clinicopathological features in Chinese female never-smokers with non-small-cell lung cancer
}

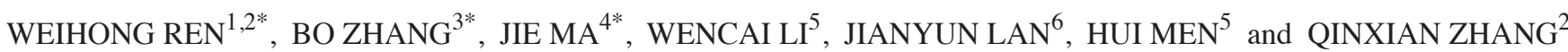 \\ ${ }^{1}$ Department of Laboratory Medicine, The First Affiliated Hospital of Henan University of Traditional Chinese Medicine, \\ Jinshui, Zhengzhou, Henan 450000; ${ }^{2}$ Department of Histology and Embryology, College of Basic Medicine, \\ Zhengzhou University, Zhengzhou, Henan 450052; ${ }^{3}$ Department of Pathology, Affiliated Hospital of Academy of \\ Military Medical Sciences, Fengtai, Beijing 100071; ${ }^{4}$ The Affiliated Tumor Hospital of Zhengzhou University, \\ Henan Cancer Hospital, Zhengzhou, Henan 450008; ${ }^{5}$ Department of Pathology, The First Affiliated \\ Hospital of Zhengzhou University, Zhengzhou, Henan 450052; ${ }^{6}$ Department of Pathology, \\ The First People's Hospital of Yancheng, Yancheng, Jiangsu 224006, P.R. China
}

Received September 13, 2014; Accepted August 17, 2015

DOI: $10.3892 / \mathrm{ol} .2015 .3740$

\begin{abstract}
Non-small-cell lung cancer (NSCLC) with echinoderm microtubule-associated protein-like 4-anaplastic lymphoma kinase (EML4-ALK) translocation is resistant to epidermal growth factor receptor (EGFR) tyrosine kinase inhibitors (TKIs), including gefitinib and erlotinib, but responds to the ALK-TKI crizotinib. Characterization of EML4-ALK translocation may provide invaluable information to facilitate disease diagnosis and improve the outcome of customized treatment. Although the occurrence of EML4-ALK translocation is likely to be affected by the smoking habits and gender of patients, the translocation has not been characterized extensively in female never-smokers with NSCLC. Therefore, 280 female never-smokers that were diagnosed with NSCLC were enrolled in the present study, and characteristics of EML4-ALK translocation, including the frequency, were determined in these NSCLC patients. $E M L 4-A L K$ fusion variants were detected using Multiplex
\end{abstract}

Correspondence to: Dr Qinxian Zhang, Department of Histology and Embryology, College of Basic Medicine, Zhengzhou University, 100 Kexue Road, Zhengzhou, Henan 450052, P.R. China

E-mail: zhqx321@126.com

${ }^{*}$ Contributed equally

Abbreviations: ALK, anaplastic lymphoma kinase; EML4, echinoderm microtubule-associated protein-like 4; NSCLC, non-small-cell lung cancer; EGFR, epidermal growth factor receptor; TKI, tyrosine kinase inhibitor; RT-PCR, reverse transcription-polymerase chain reaction; FFPE, formalin-fixed paraffin-embedded

Key words: lung cancer, EML4-ALK translocation, female, never smokers one-step reverse transcription-polymerase chain reaction and subsequently confirmed by DNA sequencing and Vysis ALK Break Apart fluorescence in situ hybridization analysis. The EML4-ALK fusion variants were detected in 21 carcinoma tissue specimens, accounting for $7.5 \%$ of the enrolled patients. Out of these patients with $E M L 4-A L K$ fusion variants, $E M L 4-A L K$ fusion variant 1 was identified in 12 patients, indicating that variant 1 is the most common type of EML4-ALK fusion gene in the present cohort of patients. ALK mRNA was aberrantly expressed in all the tissues with EML4-ALK translocation, but not in the carcinoma tissues without $E M L 4-A L K$ translocation. In addition, the $E M L 4-A L K$ translocation was more frequently found in younger patients. The median age of patients with $E M L 4-A L K$ translocation was $50.95 \pm 2.29$ years, which was significantly younger $(\mathrm{P}<0.01)$ than the median age of the patients without $E M L 4-A L K$ translocation (57.15 \pm 0.56 ). The $E M L 4-A L K$ translocation was detected exclusively in undifferentiated tumors that were graded as poorly- or moderately-differentiated carcinomas and suspected to be more malignant compared with well-differentiated tumors. In summary, the present study found that $7.5 \%$ of patients with NSCLC that are female never-smokers harbor EML4-ALK translocations, which are associated with the aberrant expression of ALK mRNA, early onset of disease and undifferentiated carcinomas.

\section{Introduction}

Lung cancer is a devastating disease and the leading cause of cancer-associated mortality worldwide (1). The most frequent type of lung cancer is non-small-cell lung cancer (NSCLC), which accounts for $\sim 80 \%$ of lung cancer cases (2). The short survival time of lung cancer patients is mainly attributed to poor outcomes from conventional chemotherapeutic treatments (3). However, progress in defining the molecular mechanism of carcinogenesis has led to a notable improvement in the response to chemotherapy (4). In 2004, it was revealed that epidermal 
growth factor receptor tyrosine kinase inhibitors(EGFR-TKIs), including gefitinib and erlotinib, are only effective in patients that harbor tumorigenic EGFR mutations that cause aberrant tyrosine kinase activity $(5,6)$. Thus, identification of oncogenic driver mutations in cancer patients has become key for the identification of an effective treatment for NSCLC (7). One of the previously identified oncogenic driver mutations is the fusion of anaplastic lymphoma kinase $(A L K)$ with echinoderm microtubule-associated protein-like 4 (EML4) on chromosome $2 \mathrm{p}$, which was identified in 2007 in a subpopulation of Japanese patients with NSCLC (8). In this study, 6.7\% (5/75) of the enrolled Japanese patients with NSCLC possessed $E M L 4-A L K$ fusion transcripts, resulting from $A L K$ translocation within chromosome $2 \mathrm{p}$ (8). Other ALK-fusion genes, including $K I F 5 B-A L K$, have also been identified within chromosome $2 \mathrm{p}$ (9-12). Patients possessing $A L K$ fusions are usually resistant to EGFR-TKIs (13), but respond to the ALK-TKI crizotinib (14). Therefore, screening for oncogenic driver mutations, including tumorigenic EGFR mutations and $A L K$ fusions, has become a crucial step in disease diagnosis and designing an effective personalized or tailored therapy plan.

Since the identification of the EML4-ALK fusion gene, numerous studies have been performed to determine the frequency of occurrence in patients with NSCLC $(8,12,15-24)$. However, these numbers varied significantly between studies (7), ranging between $1.6 \%$ in a cohort of Japanese patients (21) and $11.7 \%$ in a cohort of Chinese patients (22). This is likely to reflect the differences in detection techniques, sample size and patient selection criteria. Although the EML4-ALK translocation was first identified in a NSCLC patient with a history of smoking (8), subsequent studies have suggested that the translocation is more frequently detected in never-smokers $(13,16,21,22)$. A never-smoker is defined as an individual that has smoked $<100$ cigarettes per lifetime, according to the US Center for Disease Control (25). Although inconclusive, studies have also suggested that the frequency of the incidence is likely to be increased in female patients compared with male patients (24). Thus, it is possible that the frequency of the EML4-ALK translocation may be markedly higher in female never-smokers. A previous study reported that the incidence was as high as $15.2 \%(5 / 33)$ in a small cohort of female patients with adenocarcinoma (24).

To determine the frequency of $E M L 4-A L K$ fusion more precisely in female never-smokers, in the present study a large cohort of patients with NSCLC was assembled. In total, 280 female patients that were never-smokers were enrolled and the presence of mutations were detected by Multiplex one-step reverse transcription-polymerase chain reaction (RT-PCR) in the tumor specimens collected from these patients. The clinical characteristics that are associated with these mutations were also analyzed. The present study aimed to increase the understanding of the EML4-ALK fusion in NSCLC and provide information for improving the diagnosis procedure and designing personalized treatment plans.

\section{Materials and methods}

Patients and sample collection. The present study was approved by the Institutional Ethics Committee of Henan Cancer
Table I. Clinical features of non-small cell lung cancer tumors in female never-smokers.

Characteristics Total,n (\%)

Histology

Adenocarcinoma $274(97.86)$

Squamous cell carcinoma

Others

Age

$<40$ years

40-49 years

50-59 years

$105(37.50)$

$\geq 60$ years

$114(40.71)$

Differentiation

Poorly-differentiated

$91(32.50)$

Moderately-differentiated

95 (33.93)

Well-differentiated

$94(33.57)$

Hospital (Zhengzhou, China). In total, 280 never-smoking female patients with NSCLC were recruited (Table I). These patients were enrolled between 2012 and 2013 at Henan Cancer Hospital. Carcinoma tissue samples were collected from these patients and preserved as formalin-fixed paraffin-embedded (FFPE) tissue blocks. The FFPE tissue blocks were used as the only tissue sources for the experiments performed in the present study, including the detection of EML4-ALK fusions and measurement of the expression level of the ALK tyrosine kinase (ALK TK) mRNA and protein. As a standardized procedure during diagnosis, tumor subtypes and pathological characteristics were determined independently by two pathologists. The opinion of a third pathologist was required when there was a discrepancy. The tumors were graded based on the abnormality of the appearance of the tumor cells and tissues compared to the surrounding normal cells and normal tissues. Tumors that appeared close to normal were graded as well-differentiated. Tumors that appeared intermediately and highly abnormal were classified as moderately- and poorly-differentiated, respectively. The tumors that appeared to be abnormal were suspected to be fast-growing and malignant, collectively described as undifferentiated or less-differentiated tumors in the present study.

Detection of EML4-ALK fusion genes. The FFPE tissue blocks were sliced to a width of $3 \mu \mathrm{m}$, and the tumor regions were identified and collected for RNA extraction. Total RNA was extracted using RNeasy FFPE kit (Qiagen, Valencia, CA, USA), according to the manufacturer's instructions, and treated with DNase I (DNA-free; Ambion Life Technologies, Carlsbad, CA, USA) to remove any DNA contamination. The RNA samples were then subjected to Multiplex One-step RT-PCR with fluorescent RT-PCR to detect EML4-ALK fusion transcripts using the human Lung Cancer Related Fusion Gene Detection kit (Yuanqi Bio-Pharmaceutical Co., Ltd., Shanghai, China), according to the manufacturer's instructions. Briefly, the mixture of each reaction contained $3 \mu \mathrm{l}$ total RNA, $20 \mu \mathrm{l}$ Multiplex RT-PCR buffer and $2 \mu$ l Multiplex Enzyme Mix in a 
total volume of $25 \mu \mathrm{l}$. The primers included in the reaction for the detection of $E M L 4-A L K$ fusion subtype variants were as follows: V1 and V6 forward, 5'-ATTTGTGCAGTGTTTAGC ATTC-3'; V2 forward, 5'-CGGGAGACTATGAAATATTGT ACT-3'; V3a and V3b forward, 5'-AGTCACATAATTCTT GGGAA-3'; V4b and V7 forward, 5'-GGGAAAGGACCT AAAGGTG-3'; V4a forward, 5'-GTAGCAGAAGGAAAG GCAGATC-3'; V5a and V5b forward, 5'-GCTAAAGGCGGC TTTGGCTG-3'; and E17-A20 and V9 forward, 5'-CGCTAC TCAATAGATGGTACCT-3'; and the common reverse primer ALK-E20, 5'-CATGATGGTCGAGGTGCGC-3' (Sangon Biotech Co., Ltd., Shanghai, China). RT-PCR was performed using the 7300 Real Time PCR System (Applied Biosystems Life Technologies, Foster City, CA, USA) under the following conditions: $42^{\circ} \mathrm{C}$ for $30 \mathrm{~min} ; 94^{\circ} \mathrm{C}$ for $5 \mathrm{~min} ; 40$ cycles at $94^{\circ} \mathrm{C}$ for $15 \mathrm{sec}$; and $60^{\circ} \mathrm{C}$ for $1 \mathrm{~min}$. The PCR products were subjected to DNA sequencing (sequencing primer, 5'-TTG CTCAGCTTGTACTCAGGGCTCTG-3'; Sangon Biotech Co., Ltd.) to determine the variant types of the EML4-ALK fusion transcripts. All patients expressing the EML4-ALK fusion, as determined by Multiplex RT-PCR and direct DNA sequencing, were further confirmed by Vysis ALK Break Apart fluorescence in situ hybridization (FISH) analysis.

ALK break apart FISH analysis. FISH experiments were performed using FFPE tissue sections in order to identify ALK rearrangements. The Vysis ALK Break Apart FISH Probe kit (Abbott Molecular Inc., Des Plaines, IL, USA) was used according to the manufacturer's instructions. Briefly, two DNA probes that targeted sequences prior to and following the $A L K$ breaking point were labeled with green and red florescent dye, respectively, and used for FISH. In normal nuclei without ALK rearrangement, the red and green fluorescent signals from the two probes colocalize to form a yellowish signal, or the two signals are less than two signal diameters apart. However, when $A L K$ rearrangement occurs, the signals from the two probes are located more than two signal diameters apart in a single nucleus, which indicates a cell with ALK rearrangement. A tumor sample was considered to lack ALK rearrangement if $<5$ cells out of $50(<5 / 50$ or $<10 \%)$ appeared positive for ALK rearrangement. If $>25$ cells out of 50 ( $>25 / 50$ or $>50 \%$ ) were positive for ALK rearrangement, the tumor was considered positive, but the tumor is equivocal if 5-25 cells (10 to 50\%) are positive for ALK rearrangement. When the tumor was equivocal, additional evaluation was required, which was performed according to the manufacturer's instructions.

Determining the level of ALK $m R N A$. One-step RT-PCR was performed on the total RNA extracted from FFPE tissue blocks to determine the level of ALK RNA in the tissues. Primers specific to the ALK TK domain were designed for the ALK mRNA expression analysis. The expression level of the reference gene Abelson murine leukemia viral oncogene homolog (ABL) was also determined as a control. The primers used were as follows: ALK forward, 5'-AGAAACTGCCTC TTGACCTG-3' and reverse, 5'-GGGCATCCACTTAACTGG C-3'; and ABL forward, 5'-TACCTGAGGGAGTGCAACC-3' and reverse, 5'-TTTTCTTCTCCAGGTACTCCA-3'. In addition, the DNA sequencing primers were as follows: ALK sequencing primer, 5'-CCCTTTCTATAGTAGCTCGCCCTG
TAGAT-3'; and ABL sequencing primer, 5'-CCATGTACA GCAGCACCACGGCGT-3'. RT-PCR was performed as aforementioned.

Immunohistochemistry (IHC). IHC was used to evaluate the expression of ALK TK protein, as previously described (26). Briefly, the experiments were performed on FFPE tissue sections using a Ventana ALK (D5F3) Cdx Assay (rabbit monoclonal antibody against ALK; cat no. 790-4796; Ventana Medical Systems, Inc., Tucson, AZ, USA), which detects the endogenous levels of total ALK protein and ALK fusion proteins, according to the manufacturer's instructions. The tissue sections were deparaffinized and incubated with $3 \%$ $\mathrm{H}_{2} \mathrm{O}_{2}$ (Ventana Medical Systems, Inc.) to quench endogenous peroxidase activity, which was followed by heat-induced antigen retrieval for 30-60 min (Ventana Medical Systems, Inc.). Subsequent to blocking with $10 \%$ normal goat serum (Ventana Medical Systems, Inc.), the aforementioned primary antibody were applied, followed by goat anti-rabbit secondary antibody conjugated with horseradish peroxidase (ultraView Universal DAB Detection kit; cat no. 760-500; Ventana Medical Systems, Inc.), according to the manufacturer's instructions. The immunosignals were visualized using diaminobenzidine (UltraView; Ventana Medical Systems, Inc.) and counterstained with hematoxylin (Ventana Medical Systems, Inc.). Images were captured to assess the intensity of staining, as follows: 0 , no staining; $1+$, light staining; $2+$, moderate staining; and 3+, strong staining. The distribution of ALK immunostaining was also determined. Any tissue specimens exhibiting IHC intensity $>0$ were defined as IHC positive.

Statistical analysis. The differences between data were analyzed using $\chi^{2}$ test, Mann-Whitney $U$ test or Student's $t$-test, as appropriate. $\mathrm{P}<0.05$ was considered to indicate a statistically significant difference.

\section{Results}

Clinical features of participating patients. To avoid the variation caused by a small sample size and to more precisely determine the frequency of $E M L 4-A L K$ translocation, a total of 280 patients with NSCLC were recruited for the present study. All patients were female and were defined as never-smokers (25). Based on the information collected from these patients, the majority of the patients were diagnosed with adenocarcinoma (97.86\%; Table I). The median age of this cohort of patients was 56.69 years, ranging between 23 and 76 years. Out of these patients, $40.71 \%$ of patients were aged $\geq 60$ years, while $37.50,20.36$ and $1.43 \%$ of patients were aged 50-59, 40-49 and $<40$ years, respectively (Table I). The number of patients with poorly, moderately or well-differentiated tumor cells was similar between the groups, with 91 (32.50\%), $95(33.93 \%)$ and $94(33.57 \%)$ patients in each group, respectively (Table I).

Detection and characterization of EML4-ALK translocation. In the present study, the frequency of $E M L 4-A L K$ translocation in female never-smokers with NSCLC was determined. Therefore, Multiplex one-step RT-PCR was performed on the total RNA extracted from the FFPE tissue samples prepared 
A V1 V3a V3b V4a V5aE17-20 NC M (bp)
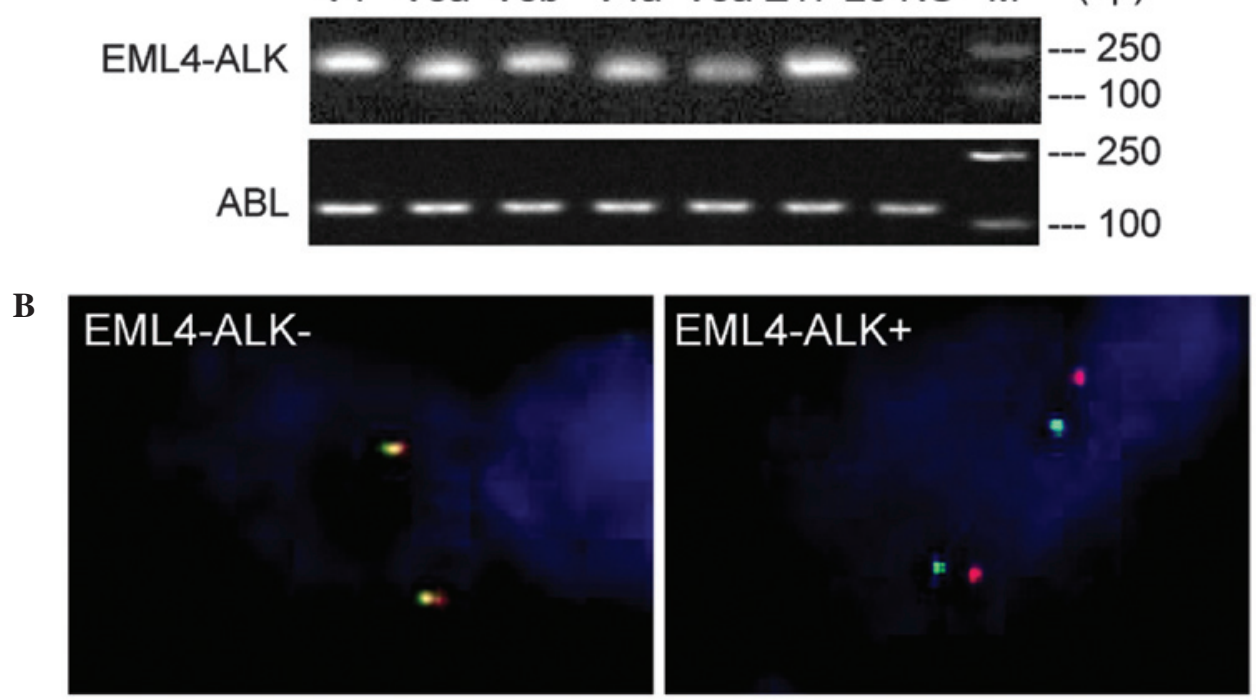

Figure 1. Screening for $E M L 4-A L K$ fusion transcripts in the tissues obtained from female never-smokers with non-small cell lung cancer. (A) Representative DNA gel images revealing the expression of the EML4-ALK fusion transcript variants V1, V3a, V3b, V4a, V5a and E17-20, and ABL controls, as determined by Multiplex one-step reverse transcription-polymerase chain reaction. (B) ALK Break Apart fluorescence in situ hybridization analysis revealed $A L K$ inversion in carcinoma tissues. Two probes targeting the sequences prior to and following the breaking point were labeled by red and green fluorescent dye, respectively. Representative images of $E M L 4-A L K$-negative (left) and -positive (right) carcinomas are shown. The $A L K$ inversion in $E M L 4-A L K$-positive carcinomas is indicated by two separated red and green dots (right) located at least two signal diameters apart. NC, negative case; M, DNA ladder; $E M L 4-A L K$, echinoderm microtubule-associated protein-like 4-anaplastic lymphoma kinase; ABL, Abelson murine leukemia viral oncogene homolog.

from the resected tumors of the enrolled patients. Out of the 280 carcinoma specimens, EML4-ALK fusion gene transcripts were detected in 21 tissue specimens, accounting for $7.5 \%$ of the total patients. The representative PCR products for each detected $E M L 4-A L K$ fusion variant are shown in Fig. 1A. The presence of $A L K$ rearrangements were confirmed using the Vysis ALK Break Apart FISH Probe kit, which detects $A L K$ rearrangements using two fluorescence-labeled probes that target sequences flanking the $A L K$ breaking point. Representative images of FISH are shown in Fig. 1B. $A L K$ rearrangements, indicated by red and green fluorescent signals located at least two signal diameters apart in a single nucleus, were detected in carcinoma samples harboring EML4-ALK translocation, but not in carcinoma samples without EML4-ALK fusion. The identity of these RT-PCR products was confirmed by DNA sequencing. All RT-PCR products from 21 tissue samples harboring EML4-ALK translocation were subsequently sequenced. The DNA sequencing traces and exon organization for each representative variant are presented in Fig. 2A. In total, 5 different variants were detected, including variant 1 in 12 samples and variant $3 a / 3 b$ in 6 samples. In addition, variants 4, 5a and E17-A20 were detected in one sample each (Fig. 2B). Variant 2 was not detected in any of the present tissue samples. Therefore, it is possible that EML4-ALK variant 1, which accounted for $57.1 \%$ of all EML4-ALK translocations, is the most common form of the fusion products in female never-smokers with NSCLC. By contrast, the variant 2 is less likely to be detected in the same group of patients.

Aberrant expression of ALK $m R N A$ is associated with EML4-ALK translocation. The expression level of ALK mRNA was measured by one-step RT-PCR. The primers were specific to the $A L K$ TK domain that was translocated and fused with EML4 in EML4-ALK fusion genes, so the mRNAs transcribed from the intact and translocated $A L K$ genes would be detected. This method revealed that ALK TK mRNA was highly expressed in tissues harboring $E M L 4-A L K$ fusion, but not in tissues without the EML4-ALK fusion (Fig. 3A). Despite expressing different variants of the $E M L 4-A L K$ fusion gene, all carcinoma specimens harboring the fusion expressed ALK TK RNA aberrantly. By contrast, ALK TK mRNA was not detectable in the majority of the samples not harboring $E M L 4-A L K$ translocation. IHC also revealed that the ALK protein is highly expressed in specimens harboring $E M L 4-A L K$ fusion, but the protein was not expressed or was expressed at an extremely low level in carcinomas without EML4-ALK fusion (Fig. 3B).

EML4-ALK translocation is more frequently detected in younger patients and undifferentiated carcinomas. All patients harboring the EML4-ALK translocation in the present cohort of patients were diagnosed with adenocarcinoma (Table II). However, it is possible that the number of other types of carcinoma was too low for $E M L 4-A L K$ fusion genes to be detected (6 out of 280 patients; $2.14 \%$ ). Therefore, the frequency of EML4-ALK translocation in other types of carcinomas was unclear. In total, 50, 12.28, 7.62 and $3.51 \%$ of the patients aged $<40,40-49,50-59$ and $\geq 60$ years, respectively, harbored $E M L 4-A L K$ fusion genes (Table II). The distribution of the patients with $E M L 4-A L K$ fusion in the four different age groups was significantly different from the distribution of patients without $E M L 4-A L K$ fusion $(\mathrm{P}<0.0019$; Table II). Furthermore, patients harboring EML4-ALK translocation (median age, 50.95 \pm 2.29 years) were significantly younger than patients without EML4-ALK translocation (median 
A EML4 Exon 13

ALK Exon 20

V1

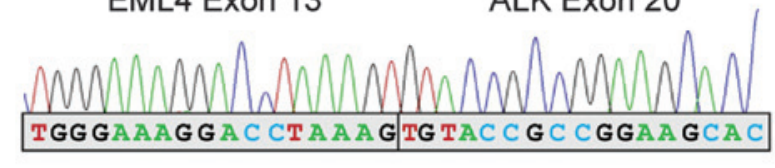

EML4 Exon 6

ALK Exon 20

V3a

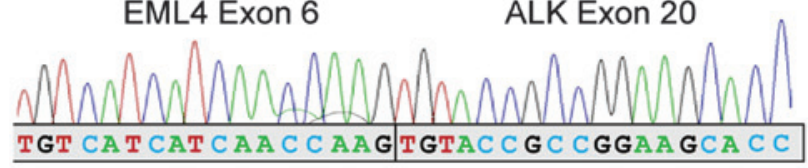

EML4 Exon 14

ALK Exon 20

V4a

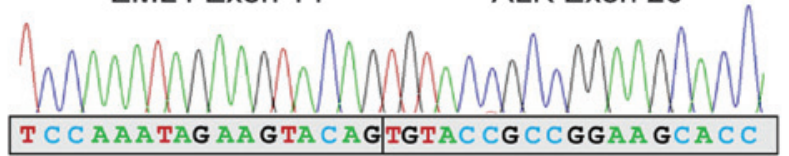

EML4 Exon 2

V5a

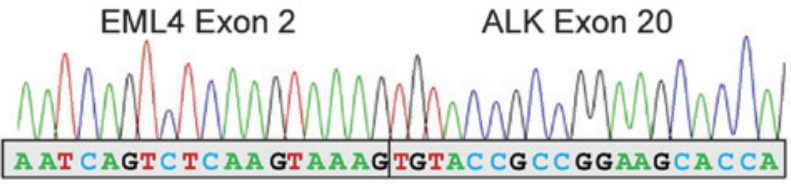

EML4 Exon 17

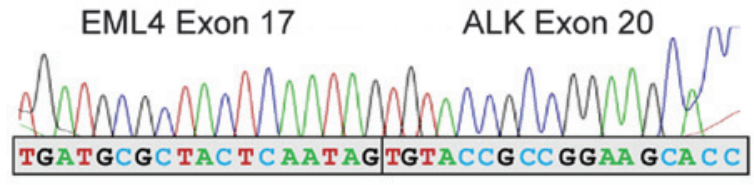

E17-20

TGATGCGCTAC TCAATAGTGTACCGCCGGAA GCACC

$\mathbf{B}$

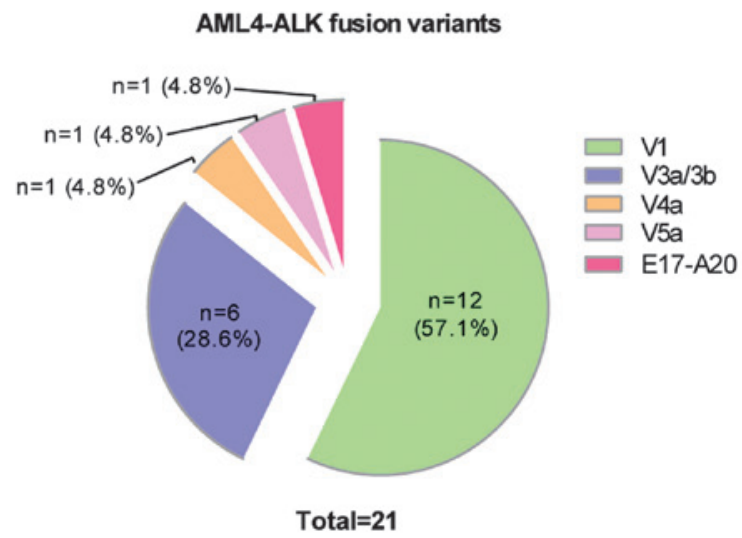

Figure 2. EML4-ALK fusion transcript variants in female never-smokers with non-small cell lung cancer. (A) Representative DNA sequencing chromatographs and schematic drawings revealing $E M L 4-A L K$ fusion junctions. Five representative $E M L 4-A L K$ fusion transcript variants were detected by Multiplex reverse transcription-polymerase chain reaction. The sequences and variant types were determined by direct DNA sequencing. The 5 detected $E M L 4-A L K$ fusion variants consisted of V1, V3a/3b, V4a, V5a and E17-20. Variant 2 was not detected in the present cohort of patients. Schematic drawings are exhibited below the corresponding DNA sequences to indicate the organization of fusion junctions. (B) Pie graph showing the frequency of $E M L 4-A L K$ fusion variants. A total of 5 different $E M L 4-A L K$ fusion variants were detected, consisting of V1, V3a/3b, V4a, V5a, and E17-20. The number and the percent of each variant are indicated in the graph. Variant 2 was not detected in these carcinoma tissues. EML4-ALK, echinoderm microtubule-associated protein-like 4-anaplastic lymphoma kinase.

age, 57.15 $\pm 0.56 ; \mathrm{P}<0.01)$ and all patients combined (median age, 56.69 $\pm 0.54 ; \mathrm{P}<0.05$ ) (Fig. 4). Histological examination revealed that all carcinomas harboring $E M L 4-A L K$ fusion were undifferentiated, either poorly- or moderately-differentiated, but never well-differentiated (Table II). The difference in the differentiation level between carcinomas harboring EML4-ALK fusion and those without the fusion gene is significant $(\mathrm{P}<0.0014)$. Overall, these results indicate that the
EML4-ALK fusion is more frequent in younger patients and in undifferentiated or less-differentiated carcinomas.

\section{Discussion}

By combining multiple published studies, the frequency of the EML4-ALK translocation in NSCLC worldwide was determined to be $\sim 5 \%$ (7). In the present study, the frequency 

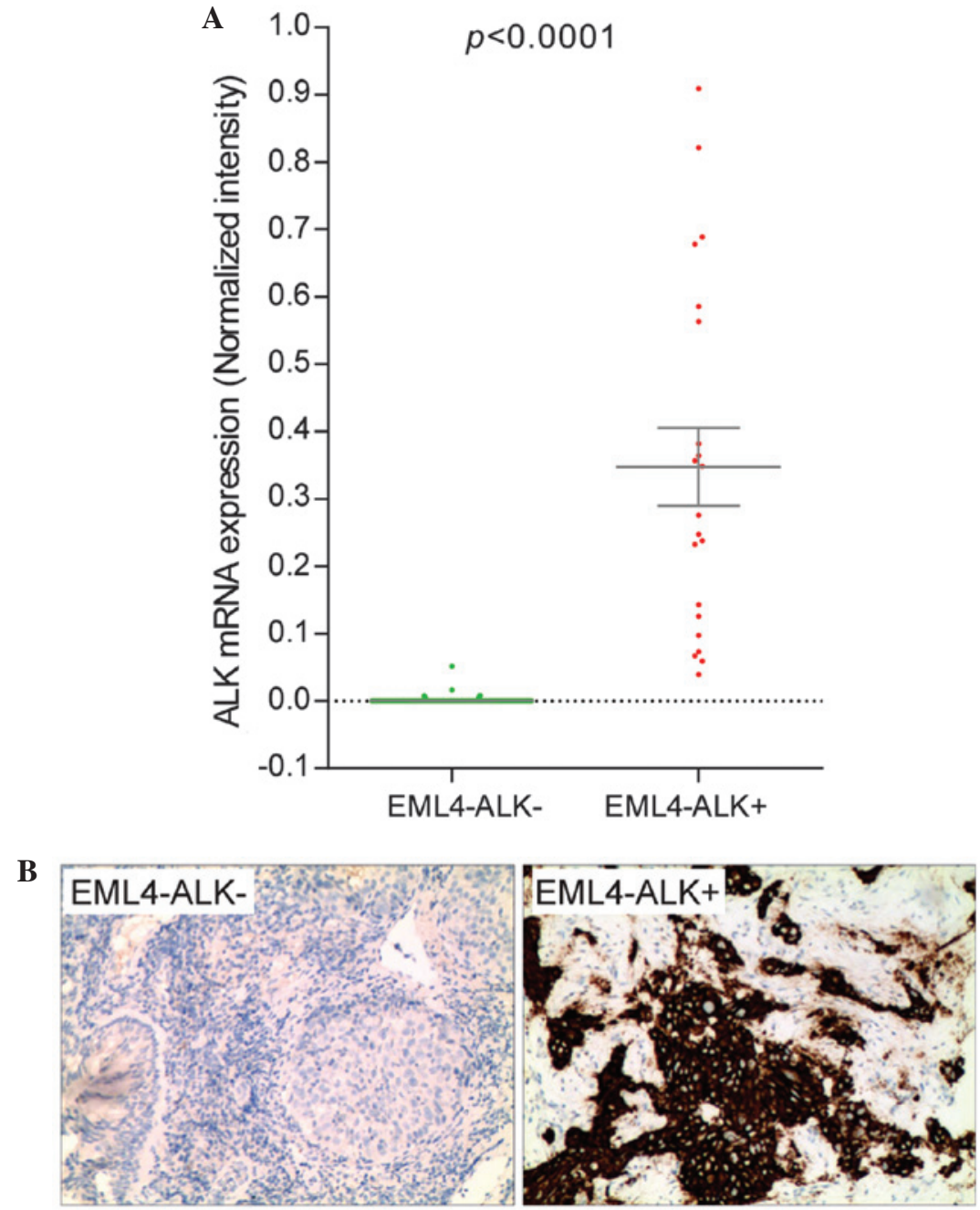

Figure 3. Aberrant expression of ALK mRNA and protein. (A) Scatter graph demonstrating that the expression of ALK mRNA is significantly higher $(\mathrm{P}<0.0001)$ in carcinoma tissues harboring $E M L 4-A L K$ fusion compared with tissues without the fusion gene in female never-smokers with non-small cell lung cancer. The values are expressed as the mean \pm standard error of the mean. (B) Representative images exhibiting the immunohistochemical staining for ALK in carcinoma tissues. The ALK protein was aberrantly expressed in carcinoma tissues harboring the EML4-ALK fusion gene (EML4-ALK+), but ALK protein expression was absent in tissues without the EML4-ALK fusion gene (EML4-ALK-). EML4-ALK, echinoderm microtubule-associated protein-like 4-anaplastic lymphoma kinase.

of EML4-ALK fusion determined using Multiplex one-step RT-PCR was $7.5 \%$ (21 out of 280 patients) in a large cohort of never-smoking female patients with NSCLC. This result was verified by DNA sequencing, ALK Break Apart FISH analysis, and immunohistochemistry. This frequency is slightly increased compared with all NSCLC patients worldwide, regardless of gender and smoking history, indicating that the combined effect of gender (female) and smoking habit (never-smokers) is minor. Notably, the present results vary from the findings of a previous study that assessed 33 female never-smoker patients with NSCLC and reported that the incidence of EML4-ALK fusion was $15.2 \%$ (5 patients) (24). The possible discrepancy may be due to the variance caused by the difference in sample sizes between the two studies, with 33 female non-smoking patients in the previous study and 280 in the present study. In addition, environmental factors, such as local air pollution levels and food choices may vary between the different regions of China and may also be involved in the discrepancy.

Out of the 21 patients with EML4-ALK fusion genes, more than one-half were detected as fusion gene variant 1 .
Variant 2 was not detected in the present tissue samples. It is therefore possible that variant 1 is the predominant type, while variant 2 is the least likely to be detected in female never-smokers with NSCLC. Regardless of the variant present, the ALK mRNA and protein were aberrantly expressed in all EML4-ALK-positive carcinomas (Fig. 3). This result is consistent with the findings that $E M L 4-A L K$ fusion genes are carcinoma driver mutations (8) and that overactivation of ALK TK plays a pivotal role in tumor cell proliferation (26-28). Compared with conventional chemotherapy, crizotinib, a selective inhibitor of ALK, has demonstrated a superior ability to improve the treatment outcome and survival rate in patients harboring EML4-ALK fusion mutations in clinical trials $(26,29-32)$. By contrast, these patients demonstrated resistance to EGFR TKIs (13). Therefore, identification of EML4-ALK fusion has a direct impact on disease treatment in NSCLC, particularly with female never-smokers that demonstrate a high frequency of the EML4-ALK fusion.

In the present cohort of patients, EML4-ALK fusions were only detected in undifferentiated or less-differentiated 
Table II. Clinical features of tissues harboring the EMLA-ALK fusion gene in female never-smokers with non-small cell lung cancer.

EMLA-ALK fusion gene

\begin{tabular}{lcrr}
\cline { 2 - 3 } Characteristics & Present, $\mathrm{n}(\%)$ & Absent, $\mathrm{n}(\%)$ & Total, $\mathrm{n}(\%)$ \\
\hline Histology & & & \\
Adenocarcinoma & $21(7.66)$ & $253(92.34)$ & $274(100)$ \\
Squamous cell carcinoma & $0(0.00)$ & $1(100.00)$ & $5(100)$ \\
Other & $0(0.00)$ & & $1(100)$ \\
Patient age & & $2(50.00)$ & $4(100)$ \\
$<40$ years & $2(50.00)$ & $50(87.72)$ & $57(100)$ \\
$40-49$ years & $7(12.28)$ & $97(92.38)$ & $105(100)$ \\
$50-59$ years & $8(7.62)$ & $110(96.49)$ & $114(100)$ \\
$\geq 60$ years & $4(3.51)$ & & $91(100)$ \\
Differentiation & & $83(91.21)$ & $95(100)$ \\
Poorly-differentiated & $8(8.79)$ & $82(86.32)$ & $94(100)$ \\
Moderately-differentiated & $13(13.68)$ & $94(100.00)$ & 0.0014 \\
Well-differentiated & $0(0.00)$ & &
\end{tabular}

EML4-ALK, echinoderm microtubule-associated protein-like 4-anaplastic lymphoma kinase.

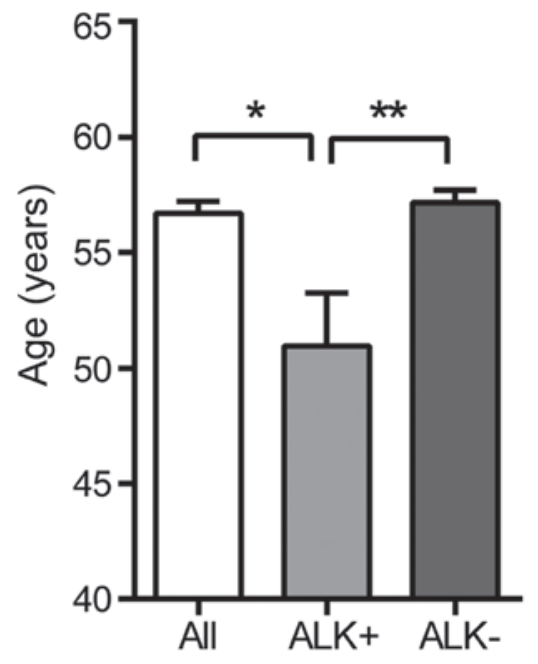

Figure 4. Summary of the median age of ALK+ and ALK- patients and the two combined. The median age in ALK+ was significantly lower compared with the median age in ALK- patients or in the two groups combined. The values are expressed as the mean \pm standard error of the mean. ${ }^{*} \mathrm{P}<0.05$ and ${ }^{* *} \mathrm{P}<0.01$. EML4-ALK, echinoderm microtubule-associated protein-like 4-anaplastic lymphoma kinase; ALK+, patients harboring EML4-ALK fusion; ALK-, patients without $E M L 4-A L K$ fusion.

carcinomas, including those graded as poorly- and moderately-differentiated tumors, but not in tumors graded as well-differentiated (Table II). This association between EML4-ALK fusion genes and undifferentiated carcinomas was also reported in a previous study, which was conducted using a cohort consisting of male and female patients with NSCLC (33). Since ALK is aberrantly expressed only in the carcinoma lesions harboring $E M L 4-A L K$ gene fusion, but not in carcinomas without the fusion gene, it is possible that ALK expression plays an important role in determining the fate of cells in NSCLC and is accountable for decreased differentiation, a feature that is often associated with more rapid-growing and malignant types of carcinomas.

In the present study, the median age of patients with $E M L 4-A L K$ gene fusion (50.95 years) was $>6$ years younger than the median age of patients without EML4-ALK gene fusion (57.15 years) in the present cohort of female never-smokers with NSCLC. The difference in age distribution between the patients harboring EML4-ALK gene fusion and those without gene fusion was statistically significant, as determined by $\chi^{2}(\mathrm{P}<0.05$; Table II). In addition, the frequency of $E M L 4-A L K$ gene fusion in the patients aged $<40$ years is $50 \%$, while the frequency gradually decreases in the older age groups (Table II). In particular, only $3.5 \%$ of patients aged $\geq 60$ years harbored the $E M L 4-A L K$ fusion gene. These results suggest that the age of disease onset is significantly younger in patients harboring EML4-ALK gene fusion compared with patients that did not harbor gene fusion.

In conclusion, the frequency of the $E M L 4-A L K$ fusion is $7.5 \%$ in a cohort of 280 NSCLC patients that consisted of female never-smokers. Among the identified fusion variants, variant 1 was the most common type, accounting for $57.1 \%$ of all EML4-ALK-positive cases. The mRNA and protein of ALK were aberrantly expressed in all EML4-ALK-positive carcinoma lesions, but were absent or expressed at a low level in patients without the fusion gene, suggesting an important role of $E M L 4-A L K$ translocation in tumorigenesis. The $E M L 4-A L K$ translocation is detected more frequently in younger patients and in undifferentiated carcinomas. These results may provide useful insights to the knowledge of NSCLC and facilitate the diagnosis and targeted treatment of the disease, leading to an improved treatment outcome and patient life quality. 


\section{Acknowledgements}

This study was supported by the Henan Province Science and Technology Department (grant no., 132300410448).

\section{References}

1. Jemal A, Bray F, Center MM, Ferlay J, Ward E and Forman D: Global cancer statistics. CA Cancer J Clin 61: 69-90, 2011.

2. Smith W and Khuri FR: The care of the lung cancer patient in the 21st century: A new age. Semin Oncol 31 (2 Suppl 4): 11-15, 2004.

3. Schiller JH, Harrington D, Belani CP, Langer C, Sandler A, Krook J, Zhu J and Johnson DH; Eastern Cooperative Oncology Group: Comparison of four chemotherapy regimens for advanced non-small-cell lung cancer. N Engl J Med 346: 92-98, 2002.

4. Petty RD, Nicolson MC, Kerr KM, Collie-Duguid E and Murray GI: Gene expression profiling in non-small cell lung cancer: From molecular mechanisms to clinical application. Clin Cancer Res 10: 3237-3248, 2004.

5. Lynch TJ, Bell DW, Sordella R, Gurubhagavatulas, Okimoto RA, Brannigan BW, Harris PL, HaserlatsM, Supko JG, Haluska FG, et al: Activating mutations in the epidermal growth factor receptor underlying responsiveness of non-small-cell lung cancer to gefitinib. N Engl J Med 350: 2129-2139, 2004.

6. Paez JG, Jänne PA, Lee JC, Tracy S, Greulich H, Gabriel S, Herman P, Kaye FJ, Lindeman N, Boggon TJ, et al: EGFR mutations in lung cancer: Correlation with clinical response to gefitinib therapy. Science 304: 1497-1500, 2004.

7. Sasaki T, Rodig SJ, Chirieac LR and Jänne PA: The biology and treatment of EML4-ALK non-small cell lung cancer. Eur J Cancer 46: 1773-1780, 2010.

8. Soda M, Choi YL, Enomoto M, Takada S, Yamashita Y, Ishikawa S, Fujiwara S, Watanabe H, Kurashina K, Hatanaka H, et al: Identification of the transforming EML4-ALK fusion gene in non-small-cell lung cancer. Nature 448: 561-566, 2007.

9. Kohno T, Ichikawa H, Totoki Y, Yasuda K, Hiramoto M, Nammo T, Sakamoto H, Tsuta K, Furuta K, Shimada Y, et al: KIF5B-RET fusions in lung adenocarcinoma. Nat Med 18: 375-377, 2012.

10. Wong DW, Leung EL, Wongs K, Tin VP, Sihoe AD, Cheng LC, Au JS, Chung LP and Wong MP: A novel KIF5B-ALK variant in nonsmall cell lung cancer. Cancer 117: 2709-2718, 2011.

11. Takeuchi K, Choi YL, Togashi Y, Soda M, Hatano S, Inamura K, Takada S, Ueno T, Yamashita Y, Satoh Y, et al: KIF5B-ALK, a novel fusion oncokinase identified by an immunohistochemistry-based diagnostic system for ALK-positive lung cancer. Clin Cancer Res 15: 3143-3149, 2009.

12. Rikova K, Guo A, Zeng Q, Possemato A, Yu J, Haack H, Nardone J, Lee K, Reeves C, Li Y, et al: Global survey of phosphotyrosine signaling identifies oncogenic kinases in lung cancer. Cell 131: 1190-1203, 2007.

13. Shaw AT, Yeap BY, Mino-Kenudson M, Digumarthy SR, Costa DB, Heist RS, Solomon B, Stubbs H, Admane S, McDermott U, et al: Clinical features and outcome of patients with non-small-cell lung cancer who harbor EML4-ALK. J Clin Oncol 27: 4247-4253, 2009.

14. Thunnissen E, Bubendorf L, Dietel M, Elmberger G, Kerr K, Lopez-Rios F, Moch H, Olszewski W, Pauwels P, Penault-Llorca F, et al: EML4-ALK testing in non-small cell carcinomas of the lung: A review with recommendations. Virchows Arch 461: 245-257, 2012.

15. Inamura $K$, Takeuchi $K$, Togashi $Y$, Nomura $K$, Ninomiya $H$ Okui M, Satoh Y, Okumura S, Nakagawa K, Soda M, et al: EML4-ALK fusion is linked to histological characteristics in a subset of lung cancers. J Thorac Oncol 3: 13-17, 2008.

16. Koivunen JP, Mermel C, Zejnullahu K, Murphy C, Lifshits E, Holmes AJ, Choi HG, Kim J, Chiang D, Thomas R, et al: EML4-ALK fusion gene and efficacy of an ALK kinase inhibitor in lung cancer. Clin Cancer Res 14: 4275-4283, 2008.

17. Shinmura K, Kageyama S, Tao H, Bunai T, Suzuki M, Kamo T, Takamochi K, Suzuki K, Tanahashi M, Niwa H, et al: EML4-ALK fusion transcripts, but no NPM-, TPM3-, CLTC-, ATIC-, or TFG-ALK fusion transcripts, in non-small cell lung carcinomas. Lung Cancer 61: 163-169, 2008.
18. Lin E, Li L, Guan Y, Soriano R, Rivers CS, Mohan S, Pandita A, Tang J and Modrusan Z: Exon array profiling detects EML4-ALK fusion in breast, colorectal and non-small cell lung cancers. Mol Cancer Res 7: 1466-1476, 2009.

19. Martelli MP, Sozzi G, Hernandez L, Pettirossi V, Navarro A, Conte D, Gasparini P, Perrone F, Modena P, Pastorino U, et al: EML4-ALK rearrangement in non-small cell lung cancer and non-tumor lung tissues. Am J Pathol 174: 661-670, 2009.

20. Wong DW, Leung EL, So KK, Tam IY, Sihoe AD, Cheng LC, Ho KK, Au JS, Chung LP, Pik Wong M, et al: The EML4-ALK fusion gene is involved in various histologic types of lung cancers from nonsmokers with wild-type EGFR and KRAS. Cancer 115: 1723-1733, 2009.

21. Takahashi T, Sonobe M, Kobayashi M, Yoshizawa A, Menju T, Nakayama E, Mino N, Iwakiri S, Sato K, Miyahara R, et al: Clinicopathologic features of non-small-cell lung cancer with EML4-ALK fusion gene. Ann Surg Oncol 17: 889-897, 2010.

22. Zhang X, Zhang S, Yang X, Yang J, Zhou Q, Yin L, An S, Lin J, Chen S, Xie Z, et al: Fusion of EML4 and ALK is associated with development of lung adenocarcinomas lacking EGFR and KRAS mutations and is correlated with ALK expression. Mol Cancer 9: 188, 2010.

23. Shaozhang Z, Xiaomei L, Aiping Z, Jianbo H, Xiangqun S and Qitao Y: Detection of EML4-ALK fusion genes in non-small cell lung cancer patients with clinical features associated with EGFR mutations. Genes Chromosomes Cancer 51: 925-932, 2012.

24. Li Y, Li Y, Yang T, Wei S, Wang J, Wang M, Wang Y, Zhou Q, Liu $\mathrm{H}$ and Chen J: Clinical significance of EML4-ALK fusion gene and association with EGFR and KRAS gene mutations in 208 Chinese patients with non-small cell lung cancer. PLoS One 8: e52093, 2013.

25. Pomerleau CS, Pomerleau OF, Snedecor SM and Mehringer AM: Defining a never-smoker: Results from the nonsmokers survey. Addict Behav 29: 1149-1154, 2004.

26. Kwak EL, Bang YJ, Camidge DR, Shaw AT, Solomon B, Maki RG, Ou SH, Dezube BJ, Jänne PA, Costa DB, et al: Anaplastic lymphoma kinase inhibition in non-small-cell lung cancer. N Engl J Med 363: 1693-1703, 2010.

27. Boland JM, Erdogan S, Vasmatzis G, Yang P, Tillmans LS, Johnson MR, Wang X, Peterson LM, Halling KC, Oliveira AM, et al: Anaplastic lymphoma kinase immunoreactivity correlates with ALK gene rearrangement and transcriptional up-regulation in non-small cell lung carcinomas. Hum Pathol 40: 1152-1158, 2009.

28. Choi YL, Takeuchi K, Soda M, Inamura K, Togashi Y, Hatano S, Enomoto M, Hamada T, Haruta H, Watanabe H, et al: Identification of novel isoforms of the EML4-ALK transforming gene in non-small cell lung cancer. Cancer Res 68: 4971-4976, 2008.

29. Shaw AT, Yeap BY, Solomon BJ, Riely GJ, Gainor J, Engelman JA, Shapiro GI, Costa DB, Ou S-HI, Butaney M, et al: Effect of crizotinib on overall survival in patients with advanced non-small-cell lung cancer harbouring ALK gene rearrangement: Aretrospective analysis. Lancet Oncol 12: 1004-1012, 2011.

30. Camidge DR, Bang YJ, Kwak EL, Iafrate AJ, Varella-Garcia M, Fox SB, Riely GJ, Solomon B, Ou SH, Kim DW, et al: Activity and safety of crizotinib in patients with ALK-positive non-small-cell lung cancer: Updated results from a phase 1 study. Lancet Oncol 13: 1011-1019, 2012.

31. Shaw AT, Kim DW, Nakagawa K, Seto T, Crino L, Ahn MJ, De Pas T, Besse B, Solomon BJ, Blackhall F, et al: Crizotinib versus chemotherapy in advanced ALK-positive lung cancer. N Engl J Med 368: 2385-2394, 2013

32. Solomon BJ, Mok T, Kim D-W, Wu Y-L, Nakagawa K, Mekhail T, Felip E, Cappuzzo F, Paolini J, Usari T, et al: First-line crizotinib versus chemotherapy in ALK-positive lung cancer. N Engl J Med 371: 2167-2177, 2014.

33. Inamura $\mathrm{K}$, Takeuchi $\mathrm{K}$, Togashi $\mathrm{Y}$, Hatano $\mathrm{S}$, Ninomiya $\mathrm{H}$, Motoi N, Mun MY, Sakao Y, Okumura S, Nakagawa K, et al: EML4-ALK lung cancers are characterized by rare other mutations, a TTF-1 cell lineage, an acinar histology and young onset. Mod Pathol 22: 508-515, 2009. 